\title{
Designation of Flood Risk Zones Using the Geographic Information System Technique and Remote Sensing Data in Wasit, Iraq
}

\begin{abstract}
Floods are a great concern for people and infrastructure, and this is an issue which has increased in several regions around the globe in recent years. This study aims to evaluate flood risk areas and create a flood risk map using integrated remote sensing data and a geographic information system (GIS) in the Wasit governorate - eastern Iraq. Specifically, GIS-based multi-criteria analysis (MCA) was used to map flood hazard areas using a four-criteria layer which is as follows: flow accumulation, slope, rainfall, and elevation. These four layers are standardized and combined using the overlay approach in ArcGIS software and a final map was produced. The study area was divided into five zones based on the results map, namely: very low, low, medium, high, and very high, according to the flood risk area. The resulting map indicates that over $60 \%$ of the study area is likely to experience a high and very high level of propensity of flooding. This study could be useful for government planners and decision-makers to predict potential flooding areas and enhance flood management plans.
\end{abstract}

Keywords: flood, Geographic Information System, Digital Elevation Model, risk mapping, remote sensing

Received: 8 March 2021; accepted: 14 May 2021

(C) 2021 Authors. This is an open access publication, which can be used, distributed and reproduced in any medium according to the Creative Commons CC-BY 4.0 License.

1 Middle Technical University, Technical Institute of Baquba, Baquba, Diyala - Iraq, email: kawther.hash@gmail.com, ORCID ID: https://orcid.org/0000-0002-2638-4044

2 Middle Technical University, Technical Institute of Baquba, Baquba, Diyala - Iraq, email: qutaibansaif@mtu.edu.iq, ORCID ID: https://orcid.org/0000-0001-9813-3773

3 Middle Technical University, Technical Institute of Baquba, Baquba, Diyala - Iraq, email: dr.mudhar.alaubedy@mtu.edu.iq (corresponding author), ORCID ID: https://orcid.org/0000-0002-1713-4860

4 School of Engineering, Faculty of Engineering and Informatics, University of Bradford, Bradford, UK, email: Y.John@bradford.ac.uk, ORCID ID: https://orcid.org/0000-0003-3671-8404 


\section{Introduction}

Globally, natural disasters are very common due to the unexpected variation in the state of natural elements because of natural forces. Generally, humans cannot control natural disasters and it is difficult to accurately predict when they will occur. When major natural disasters such as floods, droughts, and earthquakes occur, they can lead to serious threats to human life and property, in addition to affecting infrastructure, the environment, and agriculture. The impact of the disaster varies according to its severity and the coverage area. Floods are considered one of the most naturally occurring disasters that intensively affect humans and the environment $[1,2]$. They occur when a river or stream breaks out naturally or artificially because of heavy rainfall, excessive snow melt, or the failure of dams. In this regard, there are three well-known types of floods, namely flash floods, river floods, and coastal floods [3]. Over the last three decades, there has been a dramatic increase in flood events around the world and it constitutes a wake-up call for planners and ordinary people alike. The most important step in managing floods is to determine flood hazard regions. Flood risk mapping is an essential component for relevant land use planning in flood plain areas and it aids in the efforts of city planners and administrators to prioritize their mitigation or relief response. To develop a flood hazard layer, there is no consensus on the criteria that should be included [4]. Nevertheless, some of the criteria that contribute to flood susceptibility and which have been used in several studies are: slope, distance from rivers, rainfall, and elevation [5].

Using advanced technology, flood risk control can be systematically improved. Stakeholders can use affordable technology to enable early warning of flooding and know the influence it might have [6]. Flood management means an effective plan towards the occurrence of the flood event to extremely reduce flow along with the identified extent of the river. It is necessary to understand the maximum extent of floodplains to avoid people overstepping when trying to manage floods. Thus, appropriate flood management can keep people and property far away from flood hazards [7]. Flood hazard maps and satellite data can be used as effective tools to determine the path and severity of a tropical storm and therefore aid in distinguishing the risks of flooding. Specifically, satellite data can further be used to assess other hydrological and atmospheric hazards as well as geological and technological hazards. This is besides providing accurate measurements and land-use information.

A geographic information system (GIS) is a framework used to gather, manage, and analyse data. It has been successfully deployed in several areas such as hydrological modeling, urban development, land cover/ use, and environmental studies. GIS has also been used to accurately conduct risk management, response, assessment, and recovery during disasters [8]. In this aspect, various satellite applications such as remote sensing data, telecommunication networks, a navigation system, and a digital elevation model (DEM) were applied with GIS. The use of satellite-based climate remote sensing data and real-time information are more effective for risk 
management than other approaches [9]. Fortunately, various studies can be found in the open literature that have used GIS and remote sensing data in flood mapping that provide good results. For instance, Al-Abadi et al. [10] proposed the integration of catastrophe theory and analytical hierarchy process in GIS to predict flooding-prone areas in the north-eastern parts of southern Iraq. They selected seven flood factors, such as slope angle, ground surface elevation, curvature, topographic wetness index, stream power index, curve numbers, and distance from intermittent streams. Results showed that $38 \%$ of the selected areas have a high- susceptibility to flooding. Furthermore, remote sensing and GIS mapping techniques were used by Al-Saady et al. [11] to test flash flood hazards of 47 zones of the Lesser Zab River Basin located in the northern part of Iraq. This indicated that 18 zones have a roughly moderate-low risk of flood. Jaber et al. [12] analyzed the rainfall-runoff data in the governorate of Babil city/ Iraq using GIS that produced the run-off depth map for the selected area. The study showed a significant relationship between the run-off depth and rainfall. Abdulrazzaq et al. [13] developed a correlation between rainfall intensity measured by remote sensing and flood areas in Wasit/ Iraq by the integration of satellite-derived data into the database of GIS to obtain the correlation. Finally, the performance efficiency of three machine ensembled classifiers were assessed by Al-Abadi et al. [14] based on statistical measurements and used to evaluate the flood susceptibility in a remote area of southern Iraq. More importantly, all of the above studies have confirmed the superiority of GIS in predicting and map flood susceptibility.

In general, Iraq has generally calm weather and does not commonly suffer from natural hazards such as floods. However, during the last few decades, floods that occurred in some of Iraq's regions led to significant infrastructure and human loss. In May 2013, Iraq witnessed its most intensive period of rainfall, which resulted in floods and torrents due to heavy rainfall. This in turn led to the destruction of a number of villages and collapsed dozens of homes, forced families to relocate, especially in the Maysan and Wasit governorates [13, 15]. Therefore, this study focuses on the northern part of Wasit governorate due to its high vulnerability to flooding events as it has been overwhelmed by several flood events. In general, Wasit is situated at a low sea level compared to other areas in Iraq [16].

Flood risk assessment using the GIS-based multi-criteria (MCA) methodology is a relatively new approach, and only a few studies have implemented it. A study for the Red River Delta, Vietnam [17] was more sophisticated in terms of the weighting method used and the criteria selected. A study from the Don River Watershed within the Great Toronto Area (GTA) developed accurate flood risk maps using GIS and MCA along with the application of Analytical Hierarchy Process methods to define and quantify the optimal selection of weights for the criteria that contribute to flood risk [2].

In the last few decades, floods that occurred in some of Iraq's regions led to significant infrastructure and human loss. This study focuses on the northern part of Wasit governorate due to its high vulnerability to flooding events as it has been overwhelmed by several events of floods. To the best knowledge of the authors, the 
implementation of GIS to specifically predict the flood events in the northern part of Wasit has not been carried out. Therefore, this study aims to provide an accurate data and map the flood risk areas in Wasit using GIS-based MCA and remote sensing data. Consequently, it is fair to expect that this study will assist to locate the highest possible flood areas of the northern part of Wasit and to effectively warn people from any further flooding and consider the pre-step of flood management as a precaution.

\section{Materials and Methods}

In this study, various datasets were used to map the flood hazard area. All these datasets were analyzed and processed using MCA in ArcGIS 10.5 software.

\subsection{Study Area}

The study area consists of the northern part of Wasit Governorate (north of the Tigris River) in the south of Iraq, which is located between latitudes $32^{\circ} 20^{\prime}-33^{\circ} 55^{\prime} \mathrm{N}$ and longitudes $44^{\circ} 40^{\prime}-46^{\circ} 40^{\prime}$ E, as depicted in Figure 1. The name Wasit is originally derived from the Arabic word meaning "middle", since the ancient city of Wasit was located between Baghdad and Basra, before being abandoned after the Tigris shifted course [18]. The total area of the governorate is $9278 \mathrm{~km}^{2}$ including three districts, namely, Kut, Al-Azezia, and Badra districts. The borders of Wasit are Diyala governorate to the north-west, Missan governorate to the south-east, and the Islamic Republic of Iran to the north [19]. The area is covered by Quaternary deposits [20], and is characterized by varying elevations, which range from 955 to 7 meters above sea level, meaning that the area distribution ranges from mountainous to plain areas. In addition to the abundance of rainfall which leads the area to be more vulnerable to flooding, it has an average rainfall during the rainy season ranging between $15-32 \mathrm{~mm}$.

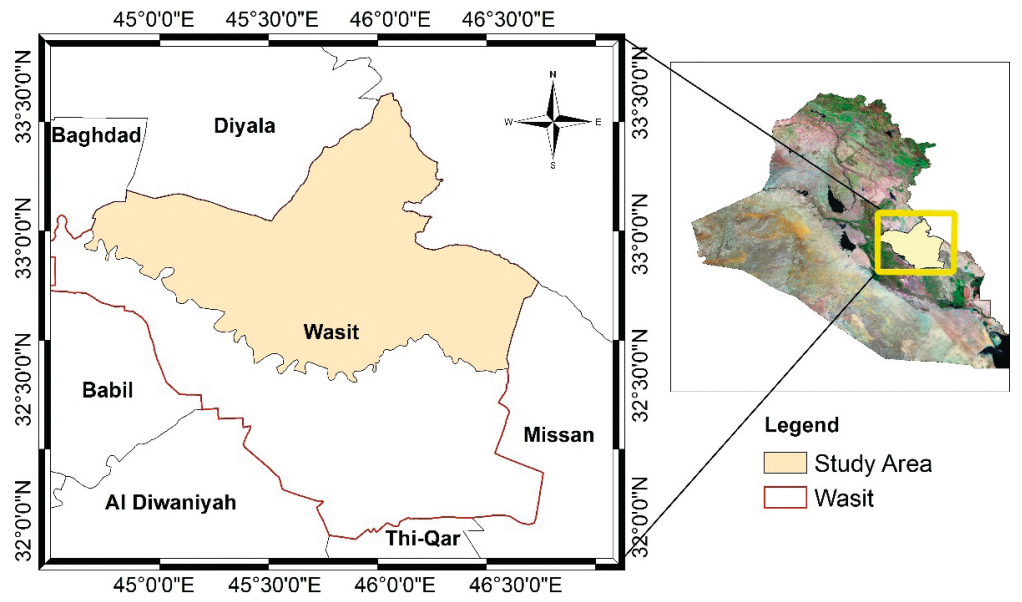

Fig. 1. Location of the northern part of Wasit governorate 


\subsection{Dataset}

\section{Digital Elevation Model (DEM)}

Topography plays an important role in flood modeling. In this study, the NASA Shuttle Radar Topography Mission (SRTM V3) with a spatial resolution of 30 meters was used to generate the elevation map (Fig. 2) and slope map (Fig. 3) using Arc GIS software. Additionally, hydrological analysis was performed using DEM and hydrology tools to drive the flow accumulation.

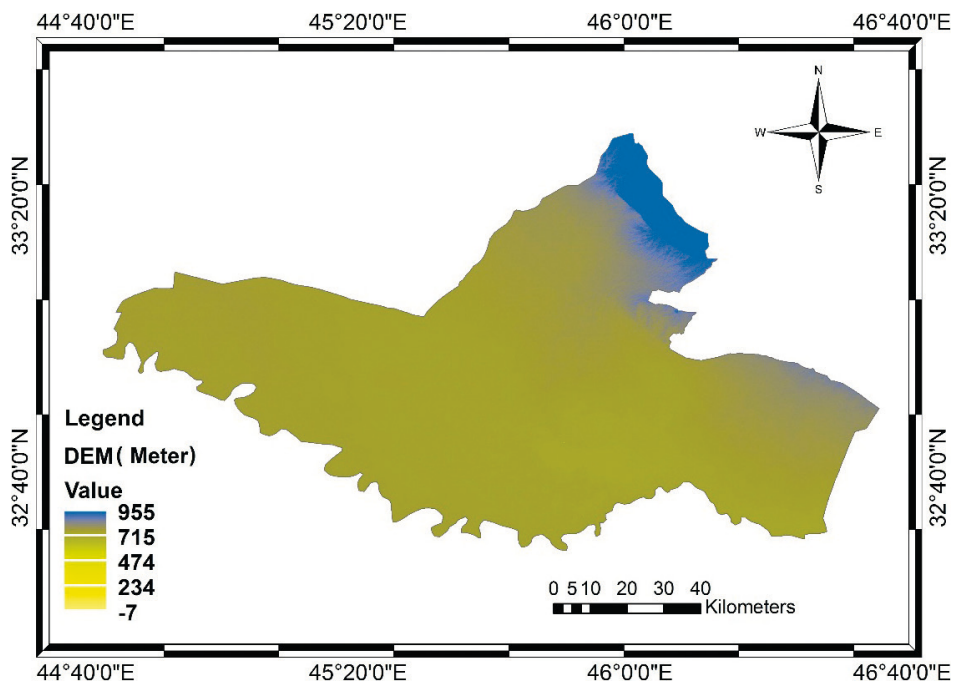

Fig. 2. DEM map of the study area

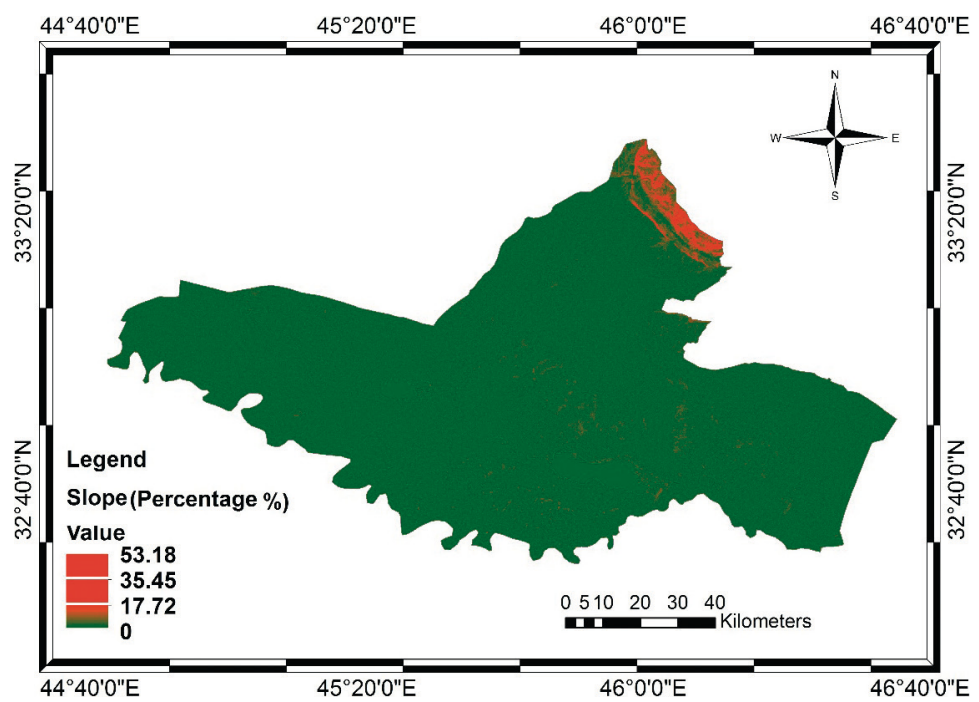

Fig. 3. Slope map of the study area 


\section{Rainfall Data}

For satellite rainfall data, the Tropical Rainfall Measuring Mission (TRMM) product was successfully used in this study.

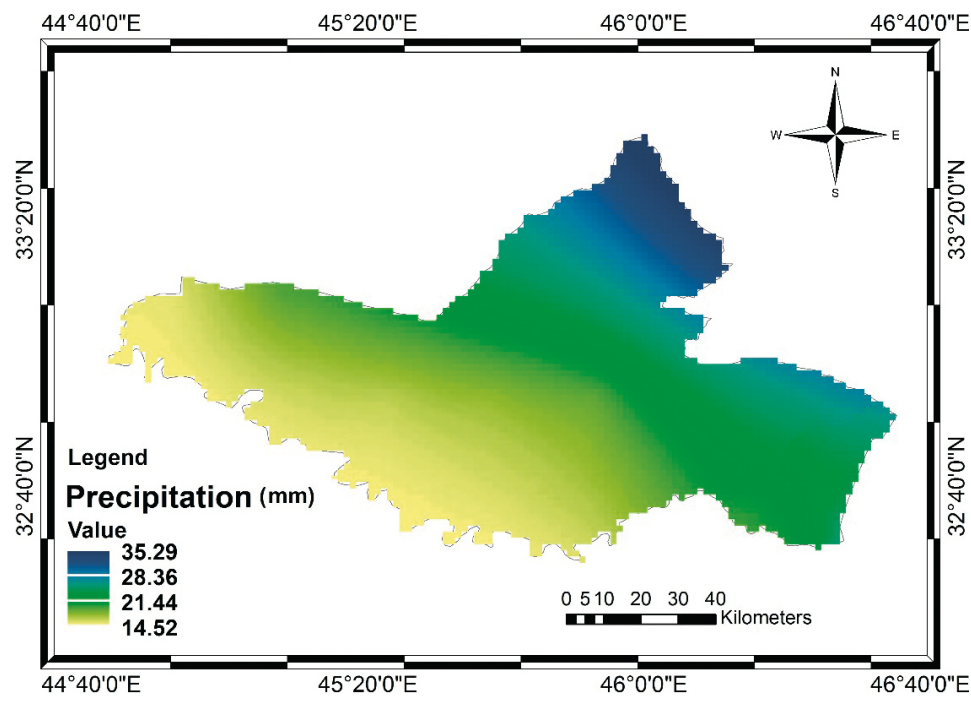

Fig. 4. Monthly rainfall rate based on TRMM data

Figure 4 shows the time-averaged map of monthly precipitation rate based on TRMM _3B43 v7 data (per mm/month) for the period 2000-2019, with a spatial resolution of $0.25^{\circ} \times 0.25^{\circ}$. The Ordinary Kriging/ Spherical model is a suitable method to interpolate the monthly and annual precipitation. This method was used to interpolate the precipitation data.

\section{GIS for Flood Mapping}

In this study, the following factors were used to map the flood via GISbased MCA:

- rainfall,

- stream order,

- elevation,

- and slope.

These layers are standardised and combined using the overlay tool in ArcGIS software. The main steps of carrying out this research are given in Figure 5. The MCA involved a series of steps that were used to assist the decision-making process. According to Malczewski [21], GIS could be used as "an environment that transforms that combines spatial data and expert preferences to support the decision-making process"'. 


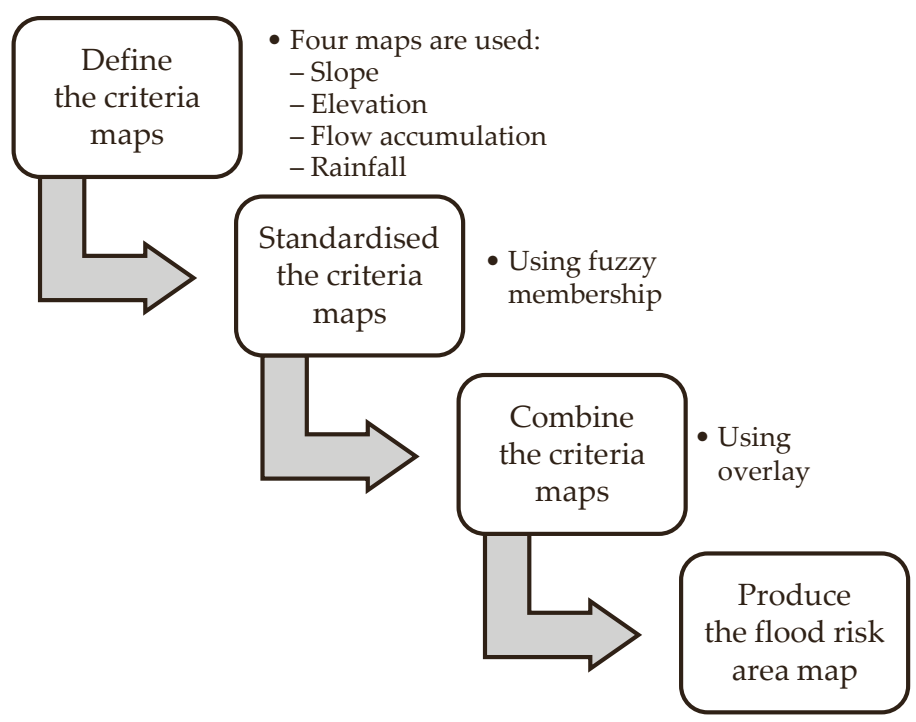

Fig. 5. The methodology of this study

\section{Criteria Layers}

The selected criteria which estimate the hazardous area are thoroughly discussed in the following bullets:

- Firstly, the flow accumulation is considered as an indirect way to measure drainage areas, which steadily increases from the drainage divides to the outlet and river channels [22]. The flow accumulation was driven from SRTM DEM data using the steps illustrated in Figure 6.

- Secondly, the topographic parameters (slope and elevation) are inversely proportional to the presence of the flood [23]. Besides, the rainfall condition is one of the most important parameters to generate flash flood events [24].

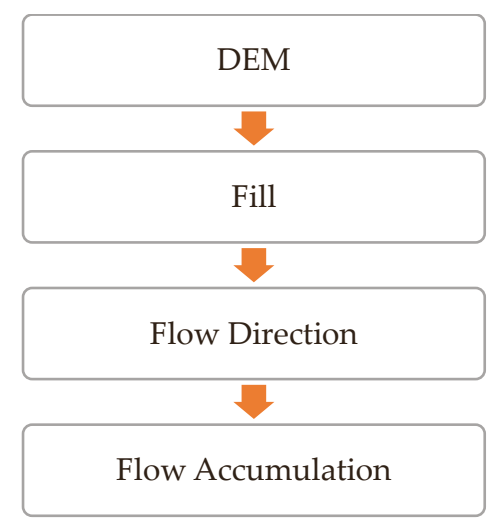

Fig. 6. Steps to drive the flow accumulation from SRTM DEM data 
To combine these criteria layers, a uniform scale should be used in a process called Standardisation. FUZZY membership is a common method to standardise the creation layers on a uniform scale (range between 1 to zero). ArcGIS provides two Fuzzy liner options, which could be set by the user according to the criteria used. In this study, the FUZZY Membership used, and its criteria set are demonstrated in Table 1.

Table 1. The criteria set used in this study

\begin{tabular}{||l|l||}
\hline \multicolumn{1}{|c|}{ Criteria } & \multicolumn{1}{c|}{ Setting } \\
\hline \hline Elevation & Minimisation: Lower lands are the most affected by flood hazards \\
\hline $\begin{array}{l}\text { Flow } \\
\text { accumulation }\end{array}$ & $\begin{array}{l}\text { Maximisation: The higher value of the flow accumulation, the more affected the } \\
\text { areas is by flood hazards }\end{array}$ \\
\hline Slope & $\begin{array}{l}\text { Minimisation: Flatlands are the most affected by flood hazards } \\
\text { hazimisation: The higher value of rainfall, the most affected is the area by flood }\end{array}$ \\
\hline Rainfall &
\end{tabular}

\section{Results and Discussion}

The designation of flood risk zones using the GIS-based MCA methodology is a relatively new approach, and only a few studies have implemented it thus far. In this study, integrated remote sensing data and GIS were used to designate flood risk zones. Specifically, a GIS-based MCA was used to map flood-hazard areas using a four-criteria layer that includes flow accumulation, slope, rainfall, and elevation. FUZZY linear membership was successfully used to standardise the criteria layers as shown in Figure 7. Then, the final step overlaid these layers to produce the flood area risk map. The resulting flood area risk map includes the four criteria that are directly related to any flood events that might occur in the selected area of this research. The four criteria maps were combined using the overlay tool in Arc GIS 10.5 software. In this regard, Figure 8 shows that the selected area (the northern part of Wasit) has been divided into five zones, namely: very high, high, medium, low, and very low according to the flood risk area. These classes were divided according to the overlay approach by merging the criteria layers, a lower value indicates a high potential risk zone because values about 0 are proposed to be very high risk whereas when the value is about 1 , it indicates a very low-risk zone. Then, the percentage of area for each class was calculated as follows: very high represents $24 \%$, high represent 39\%, medium represents 34\%, low and very low represent $3 \%$ of the total studied area. 

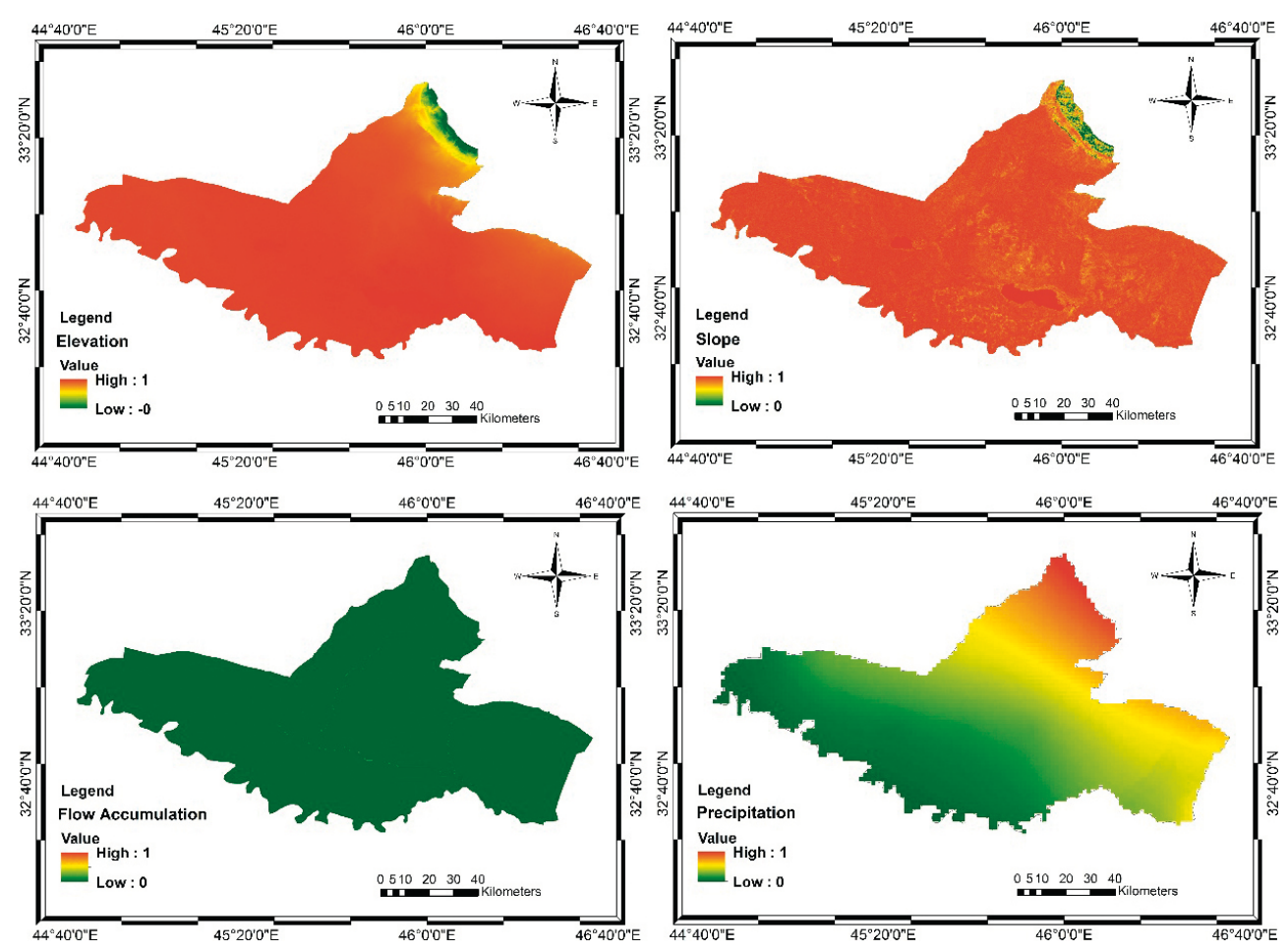

Fig. 7. Criteria layers standardisation

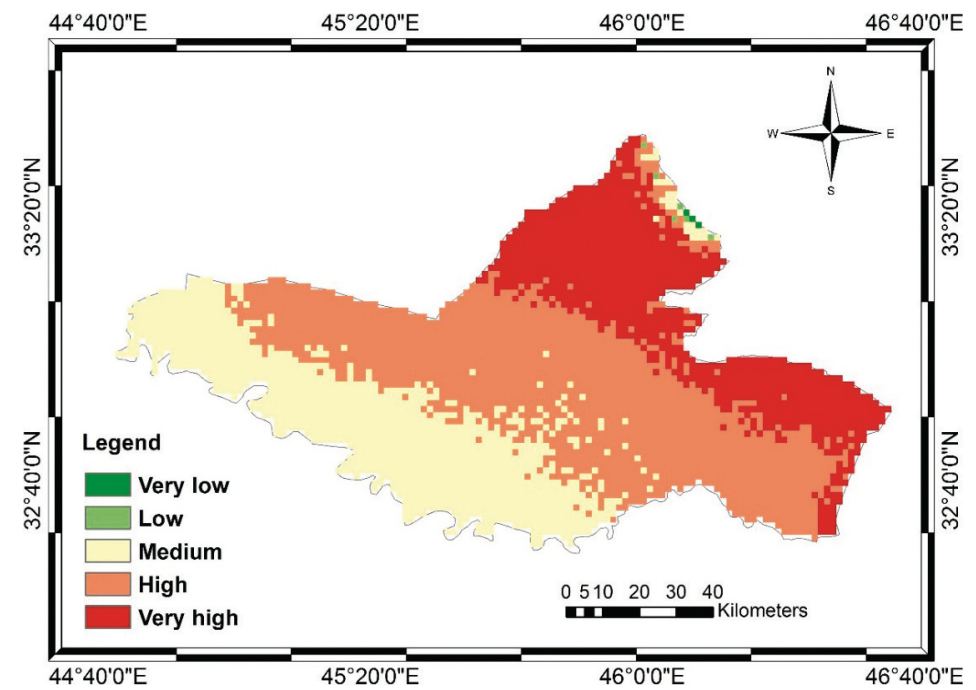

Fig. 8. Flood-hazard area map 
The resulting map indicates that over $60 \%$ of the study area is likely to experience a very high and high level of flood. More importantly, this confirms that the eastern part of the studied area is the most vulnerable area of flooding, while the western part is the least vulnerable. The obtained results of this study corroborate those presented by Abdulrazzaq et al. [13] (the study closest to this one) who attempted to generate a correlation between rainfall intensity and floodwater's areas in Wasit Governorate via an integration of compiled data derived from satellite imagery into a GIS. Abdulrazzaq et al. [13] stated that the east part of Wasit has the maximum accumulated daily rainfall range of $41 \mathrm{~mm} /$ day. The wind belt of cyclonic storms and topographic location are the main factors behind this maximum rainfall range. It is also important to know that the eastern part of Wasit has the highest precipitation, which might clarify the reason for the high propensity of flooding. This study can be used to predict prospective flooding areas, thereby helping government planners and decision-makers to improve flood management planning.

\section{Conclusions}

The estimation of flood-hazard areas is an essential part of any flood management procedure. This study presents a methodology to estimate the hazardous areas in North Wasit to determine the most potential areas at risk of flooding. GISbased MCA was used to map the flood using four criteria layers, which included the rainfall, stream order, elevation, and slope. These layers are standardised and combined using the overlay tool in ArcGIS 10.5 software. The resulting map divided the study area into five zones, namely, very high, high, medium, low, and very low according to the flood risk area. This in turn showed that the eastern part of the studied area has the highest susceptibility to flooding compared to the other studied areas.

\section{Conflict of Interest}

The authors declare no conflict of interest.

\section{References}

[1] Hewitt K.: Regions of Risk: A Geographical Introduction to Disasters. Longman, Essex 1997.

[2] Rincón D., Khan U., Armenakis C.: Flood risk mapping using GIS and multi-criteria analysis: A greater Toronto area case study. Geosciences (Switzerland), vol. 8(8), 2018, 275. https://doi.org/10.3390/geosciences8080275.

[3] Zhou Q., Su J., Leng G., Peng J.: The Role of Hazard and Vulnerability in Modulating Economic Damages of Inland Floods in the United States Using a Survey-Based Dataset. Sustainability, vol. 11(13), 2019, 3754. https://doi.org/ 10.3390/su11133754. 
[4] Tehrany M.S., Lee M., Pradhan B., Jebur M.N., Lee S.: Flood susceptibility mapping using integrated bivariate and multivariate statistical models. Environmental Earth Sciences, vol. 72, 2014, pp. 4001-4015. https://doi.org/10.1007/s12665-014-3289-3.

[5] Rahmati O., Zeinivand H., Besharat M.: Flood hazard zoning in Yasooj region, Iran, using GIS and multi-criteria decision analysis. Geomatics, Natural Hazards and Risk, vol. 7(3), 2016, pp. 1000-1017. https://doi.org/10.1080/194757 05.2015.1045043.

[6] Dano U.L., Balogun A.L., Matori A.N., Wan Yusouf K., Rimi Abubakar I., Mohamed S., Ahmed M., Aina Y.A., Pradhan B.: Flood susceptibility mapping using GIS-based analytic network process: A case study of Perlis, Malaysia. Water, vol. 11(3), 2019, 615. https://doi.org/10.3390/w11030615.

[7] Bui D.T., Pradhan B., Nampak H., Bui Q.T., Tran Q.A., Nguyen Q.P.: Hybrid artificial intelligence approach based on neural fuzzy inference model and metaheuristic optimization for flood susceptibility modeling in a high-frequency tropical cyclone area using GIS. Journal of Hydrology, vol. 540, 2016, pp. 317-330. https://doi.org/10.1016/j.jhydrol.2016.06.027.

[8] Tomaszewski B., Judex M., Szarzynski J., Radestock C., Wirkus L.: Geographic information systems for disaster response: A review. Journal of Homeland Security and Emergency Management, vol. 12(3), 2015, pp. 571-602. https://doi.org/10.1515/jhsem-2014-0082.

[9] Trnka J.: Hazmat Transportation Accidents: Introducing GIS as a core Information System in Emergency management. Final Thesis. Linköpings Universitet. Institutionen för datavetenskap - IDA, Linköpings 2002.

[10] Al-Abadi A.M., Shahid S., Al-Ali A.K.: A GIS-based integration of catastrophe theory and analytical hierarchy process for mapping flood susceptibility: a case study of Teeb area, Southern Iraq. Environmental Earth Sciences, vol. 75(8), 2016, 687. https://doi.org/10.1007/s12665-016-5523-7.

[11] Al-Saady Y.I., Al-Suhail Q.A., Al-Tawash B.S., Othman A.A.: Drainage network extraction and morphometric analysis using remote sensing and GIS mapping techniques (Lesser Zab River Basin, Iraq, and Iran). Environmental Earth Sciences, vol. 75(18), 2016, 1243. https://doi.org/10.1007/s12665-016-6038-y.

[12] Jaber H.S., Mansor S., Pradhan B., Ahmad N.: Rainfall-runoff modelling and water balance analysis for Al-Hindiyah barrage, Iraq using remote sensing and GIS. Geocarto International, vol. 32(12), 2017, pp. 1407-1420. https://doi.org/ 10.1080/10106049.2016.1213889.

[13] Abdulrazzaq Z.T., Aziz N.A., Mohammed A.A.: Flood modelling using satellite-based precipitation estimates and digital elevation model in eastern Iraq. International Journal of Advanced Geosciences, vol. 6(1), 2018, pp. 72-77. https://doi.org/10.14419/ijag.v6i1.8946.

[14] Al-Abadi A.M.: Mapping flood susceptibility in an arid region of southern Iraq using ensemble machine learning classifiers: a comparative study. Arabian Journal of Geosciences, vol. 11(9), 2018, 218. https://doi.org/10.1007/s12517-018-3584-5. 
[15] Iraqi Red Crescent Society: Wasit and Maysan are most affected by torrents and the Iraqi Red Crescent mobilizes its relief teams to provide shelter, food and relief assistance. 14 April 2019. https://reliefweb.int/report/iraq/wasit-and-maysanare-most-affected-torrents-and-iraqi-red-crescent-mobilizes-its-relief [access: 18.11.2020].

[16] Obeydi A.L., AAl-Hummadi S.K., AL-Saady A.H.: Early flood detection using SAR images and remote sensing techniques-case study Kut city in Iraq. IOP Conference Series: Materials Science and Engineering, vol. 737, 2020, 012221. https://doi.org/10.1088/1757-899X/737/1/012221.

[17] Dang N.M., Babel M.S., Luong H.T.: Evaluation of food risk parameters in the Day River Flood Diversion Area, Red River Delta, Vietnam. Natural Hazards, 56, 2010, pp. 169-194. https://doi.org/10.1007/s11069-010-9558-x.

[18] Al-Hassany G.S.: Study the Flood of 2015 in Wasit Province in Iraq. Indian Journal of Natural Sciences, vol. 9(51), 2018, pp. 15811-15816.

[19] Shamkhi M.S., Azeez J.M.R., Abdul-Sahib A.A.: Morphologic and Engineering Characteristics of Watersheds (A Case Study: East Wasit Watersheds that Feed the Al-Shewicha Trough - Iraq). IOP Conference Series: Materials Science and Engineering, vol. 870, 2020, 012115. https://doi.org/10.1088/1757899X/870/1/012115.

[20] Muslim R.I., Issa M.J., AL-Obaidi B.S.: Environmental Assessment of heavy metals Concentration and Distribution in Surface Soils of Wasit Governoratel Iraq. Iraqi Journal of Science, vol. 60(4), 2019, pp. 803-818.

[21] Malczewski J.: GIS-based multicriteria decision analysis: a survey of the literature. International Journal of Geographical Information Science, vol. 20(7), 2006, pp. 703-726. https://doi.org/10.1080/13658810600661508.

[22] Schäuble H., Marinoni O., Hinderer M.: A GIS-based method to calculate flow accumulation by considering dams and their specific operation time. Computers \& Geosciences, vol. 34(6), 2008, pp. 635-646. https://doi.org/10.1016/j.cageo. 2007.05.023.

[23] Kwak Y., Kondoh A.: A study on the extraction of multi-factor influencing floods from RS image and GIS data; a case study in Nackdong Basin, S. Korea. The International Archives of the Photogrammetry, Remote Sensing and Spatial Information Sciences, vol. 37, part B8, 2008, pp. 421-426.

[24] Camarasa Belmonte A.M., Segura Beltran F.: Flood events in Mediterranean ephemeral streams (ramblas) in Valencia region, Spain. Catena, vol. 45(3), 2001, pp. 229-249. https://doi.org/10.1016/S0341-8162(01)00146-1. 